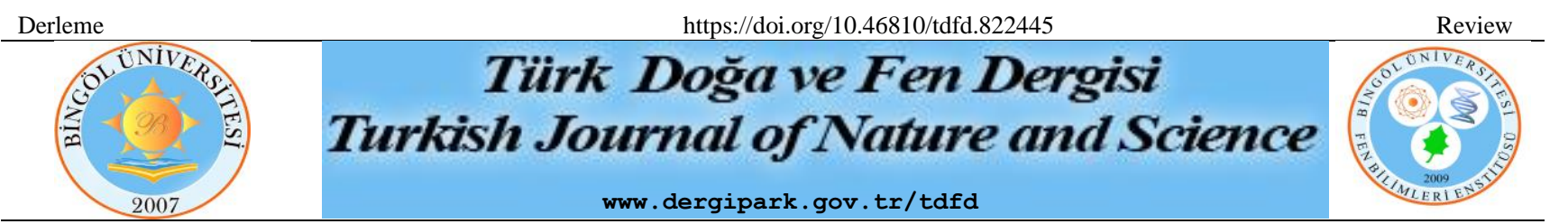

\title{
Türkiye Florasında Peyzaj Özelliği Gösteren Hiperakümülatör Bitkilerin Maden Alanlarının Onarımında Kullanımı
}

\author{
Aslıhan ESRINGÜ ${ }^{1 *}$, Işık SEZEN ${ }^{1}$ \\ ${ }^{1}$ Atatürk Üniversitesi, Mimarlık ve Tasarım Fakültesi, Peyzaj Mimarlı̆ğ Bölümü, Erzurum, Türkiye \\ Aslihan ESRIINGÜ ORCID No: 0000-0002-7930-5290 \\ Işık SEZEN ORCID No: 0000-0003-0304-9072 \\ *Sorumlu yazar: esringua@atauni.edu.tr
}

(Alınış: 06.11.2020, Kabul: 15.06.2021, Online Yayınlanma: 25.06.2021)

Anahtar Kelimeler
Ağır metal,
Hiperakümülatör
bitki,
Madencilik
aktiviteleri,
Peyzaj onarım

Anahtar Kelimeler ir metal, bitki, Peyzaj onarım
Öz: Madencilik faaliyetleri sanayi devriminden bu yana insan yaşamının sürdürülebilirliğinde, ülkelerin refah ve kalkınma düzeylerinin ilerlemesinde bir gösterge olarak kabul edilmektedir. Fakat maden işletme faaliyetleri süresince uygulanan bazı fiziksel ve kimyasal işlemler çevresel sorunlarının ortaya çıkmasına neden olmuştur. Bu sorunlar toprakların verimsizleşmesi, yerel endemik türlerin kaybolması, flora ve faunanın bozulması ve doğal peyzajın tahrip edilmesi olarak sıralanabilir. Madenlerin doğayı tahrip etmeden işletilerek devamında insanların ve diğer canlıların güvenli kullanımını sağlamaları için birçok farklı doğal restorasyon yöntemleri bulunmaktadır. $\mathrm{Bu}$ yöntemlerden biri de fitoremediasyon yöntemidir. Fitoremediasyon yönteminde kullanılan bitkiler hiperakümülatör bitki olarak adlandırılmaktadır. Bu bitkiler çok yüksek konsantrasyonlarda ağır metallerle kirletilmiş topraklarda bile hayatlarını devam ettirebilmektedirler. Doğada bilinen 11 bitki familyasından yaklaşık 400 bitki taksonu hiperakümülatör özellikleri ile bilinmektedir. Bu çalışmada Türkiye florasında bulunan 38 hiperakümülatör bitki türü ile ilgili yerli ve yabancı literatür araştırmaları yapılmış. Bu bilgiler 1şığında Türkiye florasında doğal olarak bulunan 21 hiperakümülatör bitki türünün peyzaj onarım çalışmalarında renk, doku ve form özellikleri nedeniyle kullanılabilirliği ile ilgili önerilerde bulunulmuştur.

Use of Hypreaccumulator Plants With Landscape Features in Turkey Flora in the Restoration of Mining Areas

Keywords

Heavy metal, Hyperaccumulato $r$ plants, Mining activities, Landscape repair

\begin{abstract}
Mining activities have been accepted as an indicator for the sustainability of human life and progress of countries' prosperity and development since the industrial revolution. However, some physical and chemical processes applied during mining operations bring environmental problems with it. These problems can be listed as inefficiency of the land, loss of local endemic species, degradation of flora and fauna and destruction of natural landscape. There are many different natural restoration methods to ensure that the mines are operated without destroying the nature, and to ensure the safe use of humans and other living things. One of these methods is the phytoremediation method. Plants used in the phytoremediation method are called hyperacumulators. These plants can survive even in soils contaminated with very high concentrations of heavy metals. It is known that approximately 400 plants from 11 families known in nature have hyperacumulator properties. In this study, domestic and foreign literature research was done about about 38 hyperaccumulatorsplant species in Turkey flora. In the light of this information, suggestions have been made regarding the usability of 21 hyperaccumulator plant species naturally found in Turkey's flora in landscape repair works due to their color, texture and form characteristics.
\end{abstract}




\section{GíRiş}

Yenilenemez doğal kaynaklar içerisinde büyük bir paya sahip olan madenler ülkelerin ekonomik ve sosyal kalkınmaları için gerekli hammaddeyi ve enerjiyi sağlayan önemli sektörlerden biridir. Madencilik ise farklı yerlerde değişken süreler ile geçici arazi kullanımı olarak tanımlanmaktadır [1]. Madencilik faaliyetlerinin yapıldığ 1 alanlar yerel ve bölgesel ortamlar üzerinde bazı olumsuz etkilerinin ortaya çıkmasına neden olmaktadırlar [2]. Bu olumsuzluklar işletim faaliyetleri esnasında yüksek oranlardaki ağır metallerin ve deşarj sularının taban sularına karışması nedeniyle bölgedeki toprak, su, hava kaynaklarının kaliteleri ve ekosistemin bozularak tüm canlıların yaşam alanlarının tehdit altına girmesi şeklinde görülmektedir $[3,4,5]$. Bu yer altı zenginlikleri değerlendirilirken çevrenin ve ekosistemin dengesini bozabilecek her türlü olumsuzluklar için gerekli önlemlerin alınması gerekmektedir. Şayet bu önlemler alınmaz ise bir taraftan ekonomik gelir seviyesi artış gösterirken diğer taraftan tahrip olmuş bir çevre ile mutsuz bir toplumun ortaya çıkması kaçınılmazdır. Yer altı zenginliklerinin işletilip ekonomiye kazandırılmasında açık ve kapalı madencilik olmak üzere iki ana yöntem kullanılmaktadır. Bu yöntemlerden açık ocak maden işletmeciliği dünya maden üretiminin yaklaşık \%70'inde kullanılmaktadır. Bu alanların çevreye etkileri; maden işletmeciliği ile meydana gelen arazi degradasyonu, zararlı kimyasal atıklar ile hava, su ve toprak kalitesi, hidrolojik yapı ve topografyanın bozulması, görüntü ve ses kirliliğinin oluşması, alanda kültür ve tabiat varlıkları, doğa koruma alanları var ise bu alanların tahrip olmasıdır. Açık ocak maden alanlarındaki peyzaj alanlarının ıslahı çok kolay olmamaktadır. Mevcut bu problemlerin sebebi madencilik faaliyetlerinin yapıldığı alanlarda öncesinde ve sonrasında gerekli tedbirlerin alınmayışı ve çevre ile uyumlu yöntem ve teknolojilerin kullanılmayışı olarak gösterilmektedir.

Özellikle orman ekosistemlerinde yapılan madencilik faaliyetlerinin işletim süresince ve sonrasında alanın rehabilite edilmeksizin terk edilmesi ile ortaya çıkan sorunlar maden alanı ile sinırlı kalmamakta yerel, bölgesel ve küresel düzeyde önemli problemleri de beraberinde getirmektedir. $\mathrm{Bu}$ nedenle madencilik faaliyetlerinin ortaya çıkardığı ekolojik bozulmalar için farklı yöntemler kullanılmaktadır. Kullanılan bu yöntemler sırasıyla; elektroliz yöntemi, üst toprağın sahaya serilmesi suretiyle yapilan rehabilitasyon, ve rehabilite edilemeyen sahaların kamu yararına kullanılması gibi yöntemler kullanılmaktadır. Kullanılan bu yöntemler yüksek yatırım maliyeti getirmesi ve uygulanması için alanında uzman kişilere ihtiyaç duyulmaktadır [6, 7]. Bu yöntemlere alternatif olarak son dönemlerde maliyeti daha düşük ve çevre dostu yeşil 1slah (fitoremediasyon) yöntemi kullanılmaktadır [8]. Yeşil 1slah teknolojisinde kullanılan materyal hiperakümülatör bitkilerdir. $\mathrm{Bu}$ bitkiler çok yüksek konsantrasyonlarda ağır metal içeren topraklarda canlılıklarını sürdürebilen ve kökleri vasıtasıyla topraktan almış oldukları ağır metalleri toprak üstü bitkisel (yaprak, dal ve gövdeleri gibi) dokularına taşıyabilen normal bitkilerde ölçülenden 50 ile 500 kat daha fazla metal biriktiren bitkiler olarak tanımlanmaktadırlar [9].

$\mathrm{Bu}$ çalışma ile Türkiye florasında doğal olarak bulunan 38 hiperakümülatör bitki türü peyzaj özellikleri (doku, form ve çiçek) yönünden incelenerek madencilik faaliyetleri süresince ve sonrasında çeşitli nedenlere bağlı olarak tahrip olan alanların peyzaj onarımı için kullanım olanakları araştırılmıştır.

\subsection{Kirlenmiş Toprakların Bitkilerle Temizlenmesi (Fitoremediasyon) Yöntemi}

Ağır metallerin restorasyonunda kullanılan fitoremediasyon terimi temiz ve yeşil teknolojidir. Fitoremediasyon radyonüklid, pestisitler, poliklorlubifenil, polinüleer aromatik hidrokarbon gibi kirleticiler ile kirletilmiş alanların doğal veya modifiye olmuş bitkilerin kullanımı ile kirleticilerin bileşik metabolitlere yada hareketsiz hale getirebilen teknolojidir [10,11,12,13] Fitoremediasyon yöntemi toprak veya su kirleticilerini bulundukları yerden başka yerlere taşımak veya hareketsiz hale getirebilmek için mikroorganizmaların veya vejetasyon türlerinin kullanıldığı mekanizma ve tekniklerin bütünüdür $[14,15]$. Kirleticiler bitkiler tarafından farklı zararsız formlara dönüştürülebilir ya da buharlaşarak kayba uğrayabilmektedir [16]. Fitormediasyon toksik maddelerin izolasyonı, arıtılması ve topraktan uzaklaştırılması için en iyi alternatiflerden biri olarak bilinmektedir [15].

\subsection{Hiperakümülatör Bitki}

Fitoremediasyon yönteminde kullanılan bitkiler hiperakümülatör bitki olarak adlandırılır. Clemens (2006)'e [9] göre hiperakümülator bitkiler normal bitkilerden 50-500 kat daha fazla ağır metalleri kök ve gövdelerinde absorbe etme yeteneklerine sahip bitkiler olarak tanımlanırken Van der Ent. ve ark. [17] bitki kuru maddesinde $10.000 \mathrm{mg} / \mathrm{kg} \mathrm{Mn}, 3000 \mathrm{mg} / \mathrm{kg} \mathrm{Zn,} 1000$ $\mathrm{mg} / \mathrm{kg} \mathrm{As}, \mathrm{Ni}$ ve $\mathrm{Pb}, 300 \mathrm{mg} / \mathrm{kg} \mathrm{Cr}, \mathrm{Cu}$ ve Co ve 100 $\mathrm{mg} / \mathrm{kg} \mathrm{Tl}, \mathrm{Cd}$ ve Se metalleri biriktiren bitkiler olarak tanımlamaktadırlar. Başka bir tanımda ise, bitki kuru maddesinde $10,000 \mathrm{mg} / \mathrm{kg}^{\prime}$ dan fazla $\mathrm{Mn}$ ve $\mathrm{Zn}, 1000$ $\mathrm{mg} / \mathrm{kg}$ den fazla $\mathrm{Pb}, \mathrm{Ni}, \mathrm{Cu}, \mathrm{Co}$, As, Se ve $100 \mathrm{mg} / \mathrm{kg}$ den fazla $\mathrm{Cd}$ biriktiren bitkiler hiperakümülatör bitki olarak tanımlanmıştır $[18,19]$.

Son y1llarda bünyesinde metal biriktiren yaklaşık olarak 450 bitki türünün çoğunluğunun Asteraceae, Brassicaceae, Caryophyllaceae, Fabaceae, Flacourtaceae, Lamiaceae, Poaceae, Violaceae, and Euphorbiaceae familyasına ait oldukları tespit edilmiştir [20, 21]. Bunların içerisinde Brassicaceae familyası $\mathrm{Ni}, \mathrm{Zn}$ ve $\mathrm{Cd}$ bileşiklerini yüksek oranda biriktiren 11 cins ve 87 türü ile hiperakümülatör bitkilerin yaklaşı $\% 25^{\prime}$ 'ini oluşturmaktadır [22]. 


\subsection{Türkiye Florasında Peyzaj Özelliği Gösteren Hiperakümülatör Bitkiler}

Türkiye floras 11.0707 takson ve 3.035 adet endemik tür ile dünyada çok önemli bir yere sahiptir. Türkiye florası hiperakümülatör bitkiler açısından incelendiğinde farklı familyalardan 38 adet hiperakümülatör bitki türüne rastlanmaktadır [23]. Son yıllarda çevre dostu yeşil teknoloji olarak adlandırılan fitoremediasyon yönteminin baș kahramanları olan hiperakümülatör bitkiler ile ilgili yapılan literatür taramalarından elde edilen sonuçlarda; Betula pendula bitksinin ağır metaller ile kirletilmiş toprakların ve endüstriyel alanların temizliğinde iyi bir indikatör bitki olarak kullanılabileceği yapılan çalışmalarda ortaya konulmuştur [24, 25, 26, 27]. Çinko $(\mathrm{Zn})$ ve kurşun $(\mathrm{Pb})$ cevher madenciliğinin yapıldığ alanlarda Betula pendula bitkisinin yüksek oranda elementlere töleranslı olduğu belirlenmiș ve maden alanlarının ıslahında kullanılabileceği önerilmiștir [28].

Arabidopsis thaliana Heynh. bitkisinin Maestri ve ark. [29] ve Stein ve ark. [30] tarafından yapılan çalışmalarda $\mathrm{Cd}$ ve $\mathrm{Zn}$ metalleri ile kirletilmiş alanların sslahı için iyi bir hiperakümülatör bitki olduğu bu metaller ile kirletilmiş alanların ıslahında kullanılabileceği önerilmiştir. Minuartia Hirsuta L. bitkisinin Cu töleransı üzerine etkisi yapılan bir çalışmada araştırılmış ve bitkinin kök gelişiminin $80 \mu \mathrm{M} \mathrm{Cu}$ uygulanmış alanlarda gelişim gösterdiği [31] ve Yunanistan'ın kuzeyinde yapılan başka bir araştırmada Minuartia hirsuta ssp. falcata türünün $\mathrm{Mn}, \mathrm{Zn}$ ve $\mathrm{Fe}$ elementlerinin yüksek miktarlarına tölerans gösterdiklerini tespit edilmiştir [32].

Wenzel ve Jockwer [33] yapmış oldukları çalışmada Alpinlerde $\mathrm{Pb}$ ve $\mathrm{Zn}$ metalleri ile kirletilmiş alandan Minuartia verna bitki örnekleri alınarak analiz yapılmış ve sonuçlarında $\mathrm{Pb}$ ve $\mathrm{Zn}$ sırasıyla 5000 ve $30 \mathrm{mg} / \mathrm{kg}$ oranlarında ağır metali bünyesinde biriktirdiği belirlenmiştir. Fernandez ve ark. [34] nin yapmış oldukları çalıșmada Minuartia verna $\mathrm{L}$. bitkisinin $\mathrm{Pb}, \mathrm{Zn}$ ve $\mathrm{Cd}$ elementlerin yüksek konsantrasyonlarına karşı töleranslı olduğu ve bitkinin bünyesinde biriktirdiği tespit edilmiştir. Isatis pinnatiloba P. H. Davis bitkisi ile ilgili yapılan literatür araştırmasında bitkinin bünyesinde $3000 \mathrm{mg} / \mathrm{kg}$ oranında Ni biriktirdiği [35], Altınözlü ve ark. [36] nın Pinnatiloba bitkisinin 7 farklı türünde yapılan bir çalışmada tüm türlerin $1000 \mathrm{mg} / \mathrm{kg}$ dan fazla $\mathrm{Ni}$ ve Turgay ve ark. [37] ise çalıșmalarında bitkinin $1441 \mathrm{mg} / \mathrm{kg}$ oranında $\mathrm{Ni}$ biriktirebildikleri tespit edilmiştir. Ayrıca Pollard ve ark. [38] tarafindan yapılan çalışma ile de bitkinin iyi bir Ni hiperakümülatörü olabileceği öne sürülmüștür.

Silene compacta $\mathrm{L}$. bitkisi ile Gümüşköy/Kütahya maden alanından alınan bitki örnekleri ile yapılan bir çalışmada bitkinin köklerinin iyi bir $\mathrm{Cd}$ akumülatörü olacağı ortaya konulmuştur [39].

Ricinus communis $\mathrm{L}$. bitkisinin $\mathrm{V}, \mathrm{Mn}, \mathrm{Ni}, \mathrm{Pb}, \mathrm{Cu}, \mathrm{Zn}$, $\mathrm{Cd}$ gibi ağır metallerini kökleri ile absorbe ederek yapraklarında biriktirdiği için maden alanlarının iyileştirilmesinde ve ıslahında kullanılabileceği çeşitli çalışmalarda önerilmiștir $[40,41,42]$. Yashim ve ark. [43] Nijerya'nın kuzey bölgesinde bulunan çöp sahasında doğal olarak yetişen Ricinus communis L. bitkisinden alınan örnekler ile yapılan analizler neticesinde bitkini bünyesinde yüksek oranda $\mathrm{Cd}, \mathrm{Co}, \mathrm{Ni}$ ve $\mathrm{Pb}$ biriktirdiği ortaya konulmuştur.

Parzych ve ark. [44].yapmış oldukları çalışma ile Carex echinata L. bitkisinin $\mathrm{Sr}, \mathrm{Cu}$ and $\mathrm{Ca}$ elementlerini yüksek oranlarda bünyesinde taşıdığı tespit edilmiştir.

Calystegia sepium L. bitkisinin ağır metallere karşı töleranslı olduğu ve yüksek oranda $\mathrm{Cd}$ biriktirebildiği belirlenmiştir [45].

Melilotus officinalis L. bitkisi ile yapılan çalışmalarda bitkinin $\mathrm{Cu}, \mathrm{Pb}$ ve Se ağır metallerine yüksek tölerans gösterdiği ve bu elementler ile kirletilmiş alanların 1slahında rahatlıkla kullanılabileceği bildirilmiştir [46, 34, 47, 48]. Trifolium pratense L. bitkisinin $\mathrm{Cu}, \mathrm{Pb}$ ve $\mathrm{Ni}$ ağır metallerini biriktirme potansiyelinin yüksek olduğu ve kirletilmis topraklara tölerans gösterek bitki biyokütlesinde yüksek oranlarda biriktirdiği tespit edilmiștir [49, 50, 51, 52]. Fraxinus excelsior fidelerinin $\mathrm{Pb}, \mathrm{Cd}, \mathrm{Cu}, \mathrm{Zn}, \mathrm{Ni}$ ve $\mathrm{Cr}$ ağır metalleri için iyi bir biyomonitör olduğu [53] ve Fraxinus angustifolia'nun $\mathrm{Sr}$ metalinin topraktan alınması için iyi bir hiperakümülatör bitki olduğu tespit edilmiştir [54]. Epilobium hirsutum L. bitkisinin $\mathrm{Cu}$ ile kirletilmiş alanlarda hiperakümülatör bir bitki olarak kullanılabileceği önerilmiştir [55]. Ayrıca bitkinin yüksek oranda As ve diğer metalleri biriktirdiği yapılan diğer çalışmalarda da tespit edilmiştir [56, 57].

Armeria maritima Wild. bitkisinin $\mathrm{Pb}, \mathrm{Zn}$ ve $\mathrm{Cu}$ ağır metalleri ile kirletilmiş topraklara çok iyi adapte oldukları, bünyelerinde biriktirebildikleri ve gelişimlerini tamamlayabildikleri yapılan çeşitli çalıșmalar ile ortaya konulmuștur $[58,59,60]$. Agrostis capillaris $\mathrm{L}$ bitkisinin $\mathrm{Pb}$ ve $\mathrm{Cd}$ ile kirletilmiş toprakların ıslahında güvenli bir şekilde kullanılabileceği önerilmiştir [61, 62].

Cynodon dactylon L.'C.M bitkisinin köklerinde yüksek oranda $\mathrm{Cu}$ ve $\mathrm{Pb}$ elementlerini biriktirebilme özelliği nedeniyle bu metaller ile kirletilmiş toprakların ıslahı için kullanılabileceği tespit edilmiştir [63]. Deschampsia cespitosa P. Beauv.'nun köklerinde fazla miktarda $\mathrm{Cd}$, $\mathrm{Zn}$ ve $\mathrm{Pb}$ 'u biriktirdikleri için bu metaller ile kirlenmiş alanların sslahı için uygun olduğu belirtilmiştir $[64,65$, 66]. Festuca rubra L. bitkisinin çeşitli ağır metaller ile kirletilmiş alanlarda vejetatif örtü oluşturmak için sıkça kullanılan dayanıklı bir çim bitki türü olduğu $[67,68]$ ve yüksek 1slah özelliğine sahip olduğu belirtilmiştir [69, 70]. Ayrıca bitkinin $\mathrm{Cu}, \mathrm{Zn}, \mathrm{Pb}$ ve $\mathrm{Ni}$ ile kirletilmis toprakların ıslahında yaygın bir șekilde güvenli kullanılabileceği ifade edilmiştir $[71,72]$.

Nardus stricta L. bitkisi ile yapılan bir çalıșmada bitkinin $\mathrm{Cu}$ ve $\mathrm{Pb}$ 'un yüksek miktarlarına tolerans gösterdiği ve bu metaller ile kirletilmiş alanların ıslahında kullanılabileceği bildirilmiştir [73].

Populus Tremuloides spp. türlerinin $\mathrm{Zn}, \mathrm{Cd}$, Ni ve $\mathrm{Cu}$ ağır metallerine toleranslı oldukları ve bu metallerin 
yoğun olduğu alanların 1slahında yaygin bir şekilde kullanılabileçeği ifade edilmiştir [74, 75, 76, 77,78]. Ayrıca Smith ve Nkongolo [79] tarafından yapılan bir çalışmada da bitkinin $\mathrm{Fe}, \mathrm{Mg}$, Ni ve $\mathrm{Zn}$ metalleri için de iyi bir akümülatör olduğu ortaya konulmuştur. Salix viminalis $\mathrm{L}$. türlerinin yoğun şekilde $\mathrm{Zn}$ ve $\mathrm{Cd}$ metalleri ile kirletilmiş toprakları temizlemek için yaygın bir şekilde kullanıldığı ve $\mathrm{Hg}$ ya karşın yüksek tölerans gösterdiği yapılan çeşitli çalışmalar ile bildirilmiştir [74,
33, 80, 81, 77]. Türkiye florasında bulunan hiperakümülatör özellik gösteren ve peyzaj değerine sahip bu 21 türün peyzaj değerleri (Doku, form ve renk) ve kullanım olanakları çeşitli literatürlerden araştırılarak $[82,83,84,85,86]$ ağır metal töleransları ile beraber Çizelge 1 de verilmiştir.

Tablo 1. Türkiye Florasında Bulunan Hiperkakümülatör ve Peyzaj Özelliği Gösteren Türler ve Özellikleri

\begin{tabular}{|c|c|c|c|c|}
\hline Familya & Tür & Peyzaj Değeri & $\begin{array}{c}\text { A ğır Metal } \\
\text { Töleransları }\end{array}$ & Kullanım Alanları \\
\hline Betulaceae & Betula pendula Roth & Doku, form, renk & $\mathrm{Pb}$ ve $\mathrm{Zn}$ & $\begin{array}{l}\text { Peyzaj onarım ve koruma çalışmalarında gölge } \\
\text { oluşturma, yönlendirme amaçlı }\end{array}$ \\
\hline Brassicaceae & Arabidopsis thaliana Heynh. & Çiçeği & $\mathrm{Pb}, \mathrm{Zn}$ ve $\mathrm{Cd}$ & $\begin{array}{l}\text { Peyzaj onarım ve koruma çalışmalarında, toprak } \\
\text { yüzeyini örtme ve görsel amaçlı }\end{array}$ \\
\hline Caryophyllaceae & Minuartia hirsuta $\mathrm{L}$. & Çiçeği & $\mathrm{Cu}$ & $\begin{array}{l}\text { Peyzaj onarım ve koruma çalışmalarında, toprak } \\
\text { yüzeyini örtme, stabilizasyon ve görsel amaçlı }\end{array}$ \\
\hline Caryophyllaceae & Minuartia verna $\mathrm{L}$. & Çiçeği & $\mathrm{Pb}, \mathrm{Cd}$ ve $\mathrm{Zn}$ & $\begin{array}{l}\text { Peyzaj onarım ve koruma çalısmalarında, toprak } \\
\text { yüzeyini örtme, stabilizasyon ve görsel amaçlı }\end{array}$ \\
\hline Brassicaceae & Isatis pinnatiloba P.H. Davis. & Çiçeği & $\mathrm{Ni}$ & $\begin{array}{l}\text { Peyzaj onarım ve koruma çalışmalarında, toprak } \\
\text { yüzeyini örtme, stabilizasyon ve görsel amaçlı }\end{array}$ \\
\hline Caryophyllaceae. & Silene compacta $\mathrm{L}$ & Çiçeği & $\mathrm{Cd}$ & $\begin{array}{l}\text { Peyzaj onarım ve koruma çalısmalarında, toprak } \\
\text { yüzeyini örtme, stabilizasyon ve görsel amaçlı }\end{array}$ \\
\hline Cyperaceae & Carex echinata L. & Formu & $\mathrm{Sr}, \mathrm{Cu}$ ve $\mathrm{Ca}$. & $\begin{array}{l}\text { Peyzaj onarım ve koruma çalışmalarında, toprak } \\
\text { yüzeyini örtme, stabilizasyon }\end{array}$ \\
\hline Convolvulaceae & Calystegia sepium $\mathrm{L}$. & Çiçek ve form & $\mathrm{Cd}$ & $\begin{array}{l}\text { Peyzaj onarım ve koruma çalışmalarında, } \\
\text { tırmanıcı özelliğinden dolayı duvar kenarlarında ve } \\
\text { yapay çitlerin bitkilendirilmesinde }\end{array}$ \\
\hline Euphorbiaceae & Ricinus communis $\mathrm{L}$. & Çiçek ve form & $\mathrm{Pb}, \mathrm{Cd}$ ve $\mathrm{Zn}$ & $\begin{array}{l}\text { Peyzaj onarım ve koruma çalışmalarında, toprak } \\
\text { yüzeyini örtme, stabilizasyon ve görsel amaçlı } \\
\text { görsel amaçlı }\end{array}$ \\
\hline Fabaceae & Melilotus officinalis $\mathrm{L}$. & Çiçek & $\mathrm{Pb}$ ve $\mathrm{Cu}$ & $\begin{array}{l}\text { Peyzaj onarım ve koruma çalışmalarında, toprak } \\
\text { yüzeyini örtme, stabilizasyon ve görsel amaçlı }\end{array}$ \\
\hline Fabaceae & Trifolium pratense $\mathrm{L}$. & Çiçek & $\mathrm{Cu}, \mathrm{Pb}$ ve $\mathrm{Ni}$ & $\begin{array}{l}\text { Peyzaj onarım ve koruma çalısmalarında, toprak } \\
\text { yüzeyini örtme, stabilizasyon ve görsel amaçli }\end{array}$ \\
\hline Oleaceae & Fraxinus angustifolia $\mathrm{L}$. & Formu & $\begin{array}{l}\mathrm{Pb}, \mathrm{Cd}, \mathrm{Cu} \\
\mathrm{Zn}, \mathrm{Ni} \text { ve } \mathrm{Cr}\end{array}$ & $\begin{array}{l}\text { Peyzaj onarım ve koruma çalışmalarında, erozyon } \\
\text { önleme ve toprak stabilizasyon_çalışmalarında }\end{array}$ \\
\hline Onagraceae & Epilobium hirsitum $\mathrm{L}$. & Çiçek & As ve $\mathrm{Cu}$ & $\begin{array}{l}\text { Peyzaj onarım ve koruma çalışmalarında, toprak } \\
\text { yüzeyini örtme, stabilizasyon ve görsel amaçlı }\end{array}$ \\
\hline Poaceae & Agrostis capillaris $\mathrm{L}$. & Formu & $\mathrm{Pb}$ & $\begin{array}{l}\text { Peyzaj onarım ve koruma çalışmalarında, erozyon } \\
\text { önleme ve toprak stabilizasyonu çalıșmalarında }\end{array}$ \\
\hline Poaceae & Cynodon dactylon. & Formu & $\begin{array}{l}\mathrm{Cu} \text { ve } \mathrm{Pb} \\
\text { mealleri için }\end{array}$ & $\begin{array}{l}\text { Peyzaj onarım ve koruma çalışmalarında, toprak } \\
\text { yüzeyini örtme, erozyon önleme ve toprak } \\
\text { stabilizasyonu çalışmalarında }\end{array}$ \\
\hline Poaceae & $\begin{array}{l}\text { Deschampsia caespitosa } \mathrm{P} . \\
\text { Beauv. }\end{array}$ & Formu & $\mathrm{Cd}, \mathrm{Zn}, \mathrm{Pb}$ & $\begin{array}{l}\text { Peyzaj onarım ve koruma çalışmalarında, toprak } \\
\text { yüzeyini örtme, erozyon önleme ve toprak } \\
\text { stabilizasyonu çalışmalarında }\end{array}$ \\
\hline Poaceae & Festuca rubra $\mathrm{L}$. & Formu & $\mathrm{Cu}, \mathrm{Pb}$, ve $\mathrm{Zn}$ & $\begin{array}{l}\text { Peyzaj onarım ve koruma çalışmalarında, toprak } \\
\text { yüzeyini örtme, erozyon önleme ve toprak } \\
\text { stabilizasyonu çalışmalarında }\end{array}$ \\
\hline Poaceae & Nardus stricta $\mathrm{L}$. & Formu & $\mathrm{Cu}$ ve $\mathrm{Pb}$ & $\begin{array}{l}\text { Peyzaj onarım ve koruma çalışmalarında, toprak } \\
\text { yüzeyini örtme, erozyon önleme ve toprak } \\
\text { stabilizasyonu çalışmalarında }\end{array}$ \\
\hline Plumbaginaceae & Armeria maritima Wild. & Çiçeği & $\mathrm{Pb}, \mathrm{Zn}$ ve $\mathrm{Cu}$ & $\begin{array}{l}\text { Peyzaj onarım ve koruma çalışmalarında, toprak } \\
\text { yüzeyini örtme çalışmalarında }\end{array}$ \\
\hline Salicaceae & Populus tremula $\mathrm{L}$. & Formu & $\begin{array}{l}\mathrm{Fe}, \mathrm{Cu}, \mathrm{Mn} \\
\mathrm{Zn}, \mathrm{Pb} \text { ve } \mathrm{Cd}\end{array}$ & $\begin{array}{l}\text { Peyzaj onarım ve koruma çalışmalarında, erozyon } \\
\text { önleme çalışmalarında }\end{array}$ \\
\hline Salicaceae & Salix viminalis $\mathrm{L}$. & Formu & $\mathrm{Zn}, \mathrm{Cd}$ & $\begin{array}{l}\text { Peyzaj onarım ve koruma çalışmalarında, erozyon } \\
\text { önleme çalışmalarında }\end{array}$ \\
\hline
\end{tabular}

\section{SONUC}

Madencilik faaliyetleri esnasında ortaya çıkan çevresel problemlere yeşil bir çözüm olarak önerilen fitoremediasyon yöntemi çevre dostu ve ucuz bir metottur. Bu yöntemde kullanılan bitki türleri normal bitkilere oranla çok daha fazla oranda bünyesinde ağır metalleri biriktirebilen hiperakümülatör türlerdir. Yapılan literatür araştırmaları sonucunda Türkiye florasında yer alan 38 hiperakümülatör bitki türünden 21 türün (Betula pendula Roth, Arabidopsis thaliana
Heynh, Minuartia hirsuta L., Minuartia verna L., Isatis pinnatiloba P. H. Davis, Ricinus communis L., Silene compacta L., Carex echinata L., Calystegia sepium L., Melilotus officinalis L., Tirifolium pratense L., Fraxinus angustifolia L., Epilobium hirsitum L., Armeria maritima Wild, Agrostis capillaris L., Cynodon dactylon, Deschampsia caespitosa P. Beauv, Festuca rubra L., Nardus stricta L., Populus tremula L., Salix viminalis L.) peyzaj (doku, form ve renk) ve hiperakümülatör özelliklerinden dolayı madencilik faaliyetleri gibi çeşitli uygulamalarla kirletilmiş 
toprakların peyzaj onarım çalışmalarında kolaylıkla kullanılabileceği gösterilmektedir (Çizelge 1).

Peyzaj onarım ve koruma çalışmalarında kullanımı önerilen 21 tür bitkinin 14'nün çok yıllık otsu bitki (Minuartia hirsuta L, Minuartia verna L, Isatis pinnatiloba P.H. Davis, Silene compacta L, Carex echinata L, Calystegia sepium L., Melilotus officinalis L., Epilobium hirsitum L., Agrostis capillaris L. Cynodon dactylon., Deschampsia caespitosa P. Beauv, Festuca rubra L., Nardus stricta L, Armeria maritima Wild), 2'sinin tek yıllık otsu bitki (Arabidopsis thaliana Heynh, Trifolium pratense L. ), 1'i tek ylllık odunsu (Ricinus communis L.) ve 4'ünü ağaç türleri (Betula pendula Roth,. Fraxinus angustifolia L., Populus tremula L. ve Salix viminalis L.) oluşturmaktadır. Çeşitli metaller ile kontamine olmuş toprak alanlarının ıslahında bitki seçimi önem arz etmektedir. Otsu hiperakümülatörler nispeten küçük biyokütleye ve yavaş büyümeye sahiptir, bu da türlerin fitoremediasyon potansiyellerini sinırlar [87, 88]. Betula pendula Roth,. Fraxinus angustifolia L., Populus tremula L. ve Salix viminalis L.) gibi ağaç türleri ise hızlı ve büyük biyokütle üretimi nedeniyle ağır metallerin fitoremediasyonu için otsu bitkilere göre bir avantaja sahiptir. Ağaçların yer örtücü bitkiler ile birlikte kullanılması, toprakların ağır metallerden iyileştirmesi için önemli bir rol oynamaktadır. Wu ve ark. (2021) [89] yapmış oldukları bir çalışmada üç ağaç türü (Mangifera persiciforma, Bischofia javanica ve Neolamarckia cadamba) ve üç yer örtücü bitki (Dianella ensifolia, Syngonium podophyllum ve Schefflera odorata) türünün ortak dikim için kullanılmışlardır. Bu şekilde birlikte dikim uygulaması ile bitki-bitki etkileşiminin ağır metallerin uzaklaştırılmasında başarılı bir uygulama olduğu bitki ağır metal alımını artırdığını ifade etmişlerdir. Yapılan pekçok çalışmada da hiperakümülatör özelliğe sahip farklı türlerin birlikte kullanılmasının bitkiler arasında rekabet ve tamamlama meydana getirerek ağır metaller ile kontamine topraklarda bitki biyokütlesini artırarak daha fazla ağır metal uzaklaştırılabileçeği gösterilmiştir [90, 91, 92].

Sonuç olarak ülkemizde çeşitli metaller ile kirletilmiş maden saha toprakların temizlenmesinde Türkiye florasında yer alan otsu ve odunsu hiperakümülatör türler uzun vadede koordineli bir şekilde beraber kullanımları sağlanırsa bu alanların ağır metallerden arındırılması için düşük maliyetle bir çözüm olarak önerilebilir. Ayrıca kullanılacak türlerin peyzaj niteliği taşımasından dolayı çalışılan alanlar üzerinde görsel kaliteyi de artırması beklenmektedir.

\section{KAYNAKLAR}

[1] Kivinen S. Sustainable post-mining land use: are closed metal mines abandoned or re-used space? Sustainability. 2017; 9, 1705.

[2] Sonter LJ, Barrett DJ, Moran CJ, Soares-Filho BSA. Land system science meta-analysis suggests we

underestimateintensivelandusesinlandusechangedyn amics. Journal Land Use Science. 2015; 10,191204.

[3] Khalil A, Hanich L, Bannari A, Zouhri L, Pourret O, Hakkou R. Assessment of soil contamination around an abandoned mine in a semi-arid environment using geochemistry and geostatistics: pre-work of geochemical process modeling with numerical models. Journal Geochemistry Explorer. 2013; 125:117-129.

[4] Bacchetta G, Cappai G, Carucci A, Tamburini E. Use of native plants for the remediation of abandon edminesitesin Mediterranean semiarid environments. Bull Environ Contam Toxicol. 2015; 94:326-333.

[5] Kim SM, Suh J, Oh S, Son J, Hyun CU, Park HD, Shin SH, Choi Y. Assessing and prioritizing environmental hazards associated with abandoned mines in Gangwon-do, South Korea: the Total Mine Hazards Index. Environmental Earth Sciences. 2016; Volume 75, Article number: 369.

[6] Salt DE, Rauser WE. Mg ATP-dependent transport of phytochelatins across the tonoplast of oat roots. Plant Physiology.1995; 107, 1293-1301

[7] Glass DJ. İnternational activities in phytoremediation: Industry and market overwiev. Hazardous and Industrial Wastes Book. Pages. 1999; 238-291.

[8] Arshad M, Silvestre J, Pinelli E, Kallerhoff J, Kaemmerer M, Tarigo A. A field study of lead phytoextraction by various scented pelargonium cultivars. Chemosphere. 2008; 71, 2187-2192.

[9] Clemens S. Toxic metal accumulation, responses to exposure and mechanisms of tolerance in plants. Biochimie. 2006; Volume 88, Issue 11, Pages 1707-1719.

[10] Turan M, Esringü A. Phytoremediation based on canola (Brassica Napus L.) and indian mustard (Brassica Juncea L.) planted on spiked soil by aliquot amount of $\mathrm{Cd}, \mathrm{Cu}, \mathrm{Pb}$ and $\mathrm{Zn}$. Plant Soil and Environment. 2007; 53(1):7-15.

[11] Saier MH, Trevors JT. Phytoremediation. Water Air Soil Pollution. 2010; 205 (Suppl 1):S61-S63.

[12] Singh S, Parihar P, Singh R, Singh VP, Prasad SM. Heavy Metal Tolerance in Plants: Role of Transcriptomics, Proteomics, Metabolomics, and Ionomics. Front Plant Science. 2016; 6: 1143.

[13] Manoja SR, Chinnannan K, Kadirvelu K, Arulselvia PI, ShanmugasundaramT, Bruno B, Rajkumar M. Understanding the molecular mechanisms for the enhanced phytoremediation of heavy metals through plant growth promoting rhizobacteria: A review Journal of Environmental Management. 2020; Volume 254, 109779.

[14] Ashraf S, Ali Q, Zahir ZA, Ashraf S, Asghar HN. Phytoremediation: Environmentally sustainable way for reclamation of heavy metal polluted soils. Ecotoxicology and Environmental Safety. 2019; Volume 174, 15 June Pages 714-727.

[15] Saxena G, Purchase D, Mulla SI, Saratale GD, Bharagava RN. Phytoremediation of heavy metalcontaminated sites: Eco-environmental concerns, field studies, sustainability 1ssues, and future prospects. Reviews of Environmental 
Contamination and Toxicology. 2019; Volume 249 pp 71-131.

[16] Canak S, Berezljev L, Borojevic K, Asotic J, Ketin S. Bioremediation and "Green Chemistry". Fresenius Environmental Bulletin. 2019; Volume 28 pages 3056-3064

[17] Van der Ent A, Baker AJM, Reeves RD, Pollard AJ, Schat H. Hyperaccumulators of metal and metalloid elements: facts and fiction. Plant Soil. 2013; 362:319-334

[18] Baker AJM, Brooks RR. Terrestrial higher plants which hyperaccumulate metallic elements-a review of their distribution, ecology and phytochemistry. Biorecovery. 1989; 1:81-126

[19] Robinson B, Duwig C, Bolan N, Marchetti M, Moni C, Schroeter L, Dijssel C, Milne G, Clothier B. Arsenic hyperaccumulation by aquatic macrophytes in the Taupo volcanic zone, New Zealand. Environment Explorer Botany. 2006; 58(1-3):206-215.

[20] Bolan N, Kunhikrishnan A, Thangarajan R, Kumpiene J, Park J, Makino T, Kirkham MB, Scheckel K. Remediation of heavy metal (loid)s contaminated soils - To mobilize or to immobilize? Journal of Hazardous Materials. 2014; Volume 266, 15, Pages 141-166.

[21] Ilner MJ, Kochian LV. Investigating heavy-metal hyperaccumulation using Thlaspi caerulescens as a model system. Annals of Botany.2008; 102: 3- 13.

[22] Kramer U. Metal hyperaccumulation in plants. Annual Review of Plant Biology. 2010; 61:517534

[23] Özbek K. Hiperakümülasyon ve Türkiye florasındaki hiperakümülatör türler. Toprak Bilimi ve Bitki Besleme Dergisi. 2015; 3 (1) 37 - 43

[24] Eltrop L, Brown G, Hinchee RF. Olfenbuttel Lead tolerance of' betula and salix in the mining area of Mechernich, Germany. Plant Soil.1991; 131 (1991), pp. 275-285

[25] Bojarczuk K, Przyby K. Effects of polluted substrate on growt hand health of silver birch(Betula pendula Roth). Pollution Journal Environment Study. 2005; 14,677-684.

[26] Reimann C, Arnoldussen MA, Boyd R, Finne TE, Koller F, Nordgulen, Englmaier P. Element contents in leaves off our plant species (Birch, mountainash, fern an dspruce along anthropogenic and geogenic concentration gradients. Science Total Environment. 2007a; 377,416-433.

[27] Reimann C, Arnoldussen A, Finne TE, Koller F, Nordgulen, Englmaler P. Element contents in mountain birch leaves, bark and wood under different anthropogenic and geogenic conditions. Appl. Geochemistry. 2007b; 22,1549-1566.

[28] Pajak M, Halecki W, Gasiorek M. Accumulative response of Scots pine (Pinus sylvestrisL.) and silverbirch (Betula pendulaRoth) to heavy metals enhanced by $\mathrm{Pb}-\mathrm{Zn}$ oremining and processing plants: Explicitly spatial considerations ofordinary kriging based on a GIS approach. Chemosphere 168. $2017 ; 851-859$

[29] Maestri E, Marmiroli M, Visioli G, Marmiroli N. Metal tolerance and hyperaccumulation: Costs and trade-offs between traits and environment. Environmental and Experimental Botany. 2013; Volume 68, Issue 1, Pages 1-13.

[30] Stein AJ, Höreth S, Melo JRF, Syllwasschy L, Lee G, Garbin M, Clemens S, Kramer U. Relationships between soil and leaf mineral composition are element-specific, environment-dependent and geographically structured in the emerging model Arabidopsis halleri. New Phytology. 2017; 213, Pages 1274-1286.

[31] Ouzounidou G, Symeonidis L, Babalonas D, Karataglis S. Comparative Responses of a coppertolerant and a copper-sensitive population of Minuartia hirsuta to copper toxicity. Journal of Plant Physiology. 1994; Volume 144, Issue 1, Pages 109-115.

[32] Konstantinou M. Heavy metal uptake by species from metalliferous sites in Northern Greece. Mineral Resources in a Sustainable World 13th sga Biennial Meeting. 2015; Proceedings, Volume 4

[33] Wenzel WW, Jockwer F. Accumulation of heavy metals in plants grown on mineralised soils of the Austrian Alps. Environment Pollution. 1999; 104 (1), pp. 145-155.

[34] Fernández R, Bertrand A, García JI, Tamés RS, González A. Lead accumulation and synthesis of non-protein thiolic peptides in selected clones of Melilotus alba and Melilotus officinalis. Environment Experimental Botany. 2012; 78, 1824.

[35] Karimi N, Ghaderian SM, Maroofi H, Schat H. Analysis of arsenic in soil and vegetation of a contaminated area in Zarshuran. Iran International Journal Phytoremediate. 2010; 12:159-173

[36] Altınözlü H, Karagöz A, Polat T, Ünver İ. Nickel hyperaccumulation by natural plants in Turkish serpentine soils. Turk Journal Botany. 2012; 36:269-280.

[37] Turgay OC, Görmez A, Bilen S. Isolation and characterization of metal resistant-tolerant rhizosphere bacteria from the serpentine soils in Turkey. Environment Monitoring and Assessment. 2012; 184(1):515-26.

[38] Pollard A J, Reeves RD. Baker AJM. Facultative hyperaccumulation of heavy metals and metalloids. Plant Science.2014; 217-218:8-17.

[39] Palutoglu M, Akgül B, Suyarko, Yakovenko, M, Kryuchenko N, Sasmaz A. Phytoremediation of cadmium by native plants grown on mining soil. Bulletin of Environmental. Contamination and Toxicology.2018; 100:293-297.

[40] Vwıko DE, Anoliefo Go, Fashemı SD. Metal concentration in plant tissues of ricinus communis 1. (Castor oil) grown in soil contaminated with spent lubricating oil. All rights reserved Journal Apply Science Environment Volume. 2006; 10 (3) $127-134$.

[41] Rajkumar M, Freitas H. Influence of metals resistant- plant growth-promoting bacteria on the plant growth of Ricinus cummunis in soil contaminated with heavy metals. Chemosphere. 2008; 71:834-842. 
[42] Olivares R, Carrillo-González R, González-Chávez M, Del CA, Soto- Hernández RM. Potential of castor bean (Ricinus communis L.) for phytoremediation of mine tailings and oil production. Journal of Environmental Management. 2012; 114:316-323

[43] Yashim ZI, Agbaji EB, Gimba CE, Idris SO. Phytoremediation potential of ricinus communis 1 . (Castor oil plant) in Northern Nigeria. International Journal of Plant \& Soil Science. 2016; 10(5): 1-8.

[44] Parzych AE, Sobisz Z, Jonczak J. Comparıng carex species of mid-forest spring ecosystems in terms of ability to accumulate macro- and microelements. Journal of Ecological Engineering. 2017; Volume 18 , Issue 5, pages 125-136

[45] Abe T, Fukami M, Ogassawara M. Cadmium accumulation in the shoots and roots of 93 weed species. Soil Science and Plant Nutrition. 2010; 54, 566-573.,

[46] Kostopoulou P, Kyriazopoulos AP, Abraham EM, Pariss1 Z.M, Karatassiou M, Barbayannıs N. Synergistic effect of selenium addition and water stress on melilotus officinalis L. mineral content. Notulae Botanicae Horti Agrobotanici ClujNapoca. 2015; 43(2):447-454.

[47] Wu Z, McGrouther K, Chen D, Wu W, Wang H. Subcellular distribution of metals within Brassica chinensis L. in response to elevated lead and chromium stress. Journal Agricultural Food Chemistry. 2013; 61:4715-4722.

[48] Han Y, Wu X, Gu J, Zhao J, Huang S. Yuan H, Fu J. Effects of organic acids on the photosynthetic and antioxidant properties and accumulations of heavy metals of Melilotus officinalis grown in $\mathrm{Cu}$ tailing. Environment Science Pollution Research. 2016; 23:17901-17909.

[49] Abdel-Sabour MF. Nickel accumulation parameters, coefficients of transfer, tolerance index, and nutrient uptake by red clover grown on nickel polluted soils. International Journal Environment Study. 1991; 37, 25-34.

[50] Guerra P, Ahumada, Carrasco A. Effect of biosolid incorporation to mollisol soils on $\mathrm{Cr}, \mathrm{Cu}, \mathrm{Ni}, \mathrm{Pb}$, and $\mathrm{Zn}$ fractionation, and relationship with their bioavailability. Chemosphere. 2007; 68, 20212027.

[51] Malizia D, Giuliano A, Ortaggi G, Masotti A. Common plants as alternative analytical tools to monitor heavy metals in soil. Chemistry Central Journal. 2012; 6, S6.

[52] Shahbaza AK, Iqbala M, Jabbarb A, Hussaina S, Ibrahima M. Assessment of nickel bioavailability through chemical extractants and red clover (Trifolium pratense L.) in an amended soil: Related changes in various parameters of red clover. Ecotoxicology and Environmental Safety. 2018; Volume 149, Pages 116-127.

[53] Aksoy A, Demirezen D. Fraxinus excelsior as a biomonitor of heavy metal pollution polish Journal of Environmental Studies. 2006; Vol. 15, No. 1, 27 33.

[54] Pinheiro JC, Marques CR, Pinto G, Bouguerra S, Mendo S, Gomes NC, Gonçalves F, Rocha-Santos
T, Duarte AC, Roembke J, Sousa JP, Ksibi M, Haddioui A, Pereira R. The performance of Fraxinus angustifolia as a helper for metal phytoremediation programs and its relation to the endophytic bacterial communities. Geoderma. 2013; 202-203 171-182.

[55] Ghaderian AM, Ravandi AG. Accumulation of copper and other heavy metals by plants growing on Sarcheshmeh copper mining area, Iran. Journal of Geochemical Exploration. 2012; Volume 123, Pages 25-32.

[56] Cheng S, Grosse W, Karrenbrock F, Thoennessen M, 2002. Efficiency of constructed wetlands in decontamination of water polluted by heavy metals. Ecological Engineering. 18, 317-325.

[57] Philippe AG, Masotti V, Rabier J, Petit ME, Malleret L, Coulomb B, Schwob IL. Biomonitoring of epilobium hirsutum 1 . health status to assess water ecotoxicity in constructed wetlands treating mixtures of contaminants. Water. 2015; 7(2), 697 715.

[58] Brewin LE, Mehra A, Lynch T, Farago ME. Mechanısms of copper tolerance by armeria maritıma in dolfrwynog bog, north wales initial studies. Environmental Geochemistry and Health. 2003; 25: 147-156.

[59] Ciarkowska K, Hanus-Fajerska E. Remediation of soil-free grounds contaminated by zinc, lead and cadmium with the use of metallophytes. Polish Journal of Environment Study. 2008; Vol. 17, No. 5 707-712.

[60] Parys E, Wasilewska W, Siedlecka M, Zienkiewwicz M, Drozak A, Romanowska E. Metabolic responses to lead of metallicolous and nonmetallicolous populations of Armeria maritima. Arch Environmental Contamination Toxicology. 2014; 67:565-577.

[61] Truyens S, Jambon I, Croes S, Janssen J, Weyens N, Mench M, Carleer R, Cuypers A, Vangronsveld $\mathrm{J}$. The effect of long-term $\mathrm{Cd}$ and $\mathrm{Ni}$ exposure on seed endophytes of agrostis capillaris and their potential application in phytoremediation of metalcontaminated soils. International Journal of Phytoremediation. 2014; 16: 643-659.

[62] Seijo AR, Vila ML, Andrade ML. Pb pollution in soils from a trap shooting range and the phytoremediation ability of Agrostis capillaris L. Environmental Science and Pollution Research. 2016, Volume 23, Issue 2, pp 1312-1323.

[63] Nazır A, Naseem MMR, Ajaıb M, Khan N, Siddique F. Hyperaccumulators of heavy metals of industrial areas of 1slamabad and rawalpindi. Pakistan Journal Botany. 2011; 43(4): 1925-1933.

[64] Padmavathiamma PK, Li LY. Phytoremediation technology: hyperaccumulation metals in plants. Water, Air, Soil Pollution. 2007; 184, 105-126.

[65] Mahmood T. Phytoextraction of heavy metals the process and scope for remediation of contaminated soils. 2010; Soil \& Environ. 29(2): 91-109.

[66] Smith MM, Nkongolo KK. Physiological and Cytological Responses of Deschampsia cespitosa and Populus tremuloides to Soil Metal 
Contamination. 2015; Water, Air, \& Soil Pollution volume 226, Article number: 125

[67] Simon L. Stabilization of metals in acidic mine spoil with amendments and red fescue (Festuca rubra L.) growth. Environmental Geochemistry and Health. 2005; Volume 27, pages 289-300.

[68] Touceda-Gonzalez M, Alvarez-Lopeza V, PrietoFernandez A, Rodríguez B, Trasar-Cepeda C, Mench M, Puschenreiter M, Quintela-Sabarís C, Macias-Garcia F, Kidd PS. Aided phytostabilisation reduces metal toxicity, improves soil fertility and enhances microbial activity in $\mathrm{Cu}-$ rich mine tailings. Journal Environment Management. 2017; 186, 301-313.

[69] Malagoli M, Rossignolo V, Salvalaggio N. Potential for phytoextraction of copper by Sinapis alba and Festuca rubra cv. Merlin grown hydroponically and in vineyard soils. Environment Science Pollution Research. 2014; 21:3294-3303.

[70] Gomez J, Yunta F, Esteban E, Carpena RO, Zornoza P. Use of radiometric indices to evaluate $\mathrm{Zn}$ and $\mathrm{Pb}$ stress in two grass species (Festuca rubra L. and Vulpia myuros L.) .Environment Science Pollution Research. 2016; No, 23 pages 2323923248.

[71] Bosiacki M, Zielezi Eski L. Phytoextraction of nickel by selected species of lawn grasses from substrates contaminated with heavy metals. Acta Science Pollution Hortorum Cultus. 2011; 10(3) 2011, 155-173.

[72] Golda S, Korzeniowska J. Compa rison of phytoremediation potential of three grass species in soil contaminated with cadmium. Environmental Protection and Natural Resources. 2016; Volume 27: Issue 1.

[73] Alexandrina M, Eften A, Anghel A, Marinescu M. Soil contamination in the proximity of the historical copper smelter - A Review. 18th International Multidisciplinary Scientific Geo Conference SGEM. 2018

[74] Pulford I, Watson C. Phytoremediation of heavy metal-contaminated land by trees a review. Environment Interntaional. 2003; 29, 529-540.

[75] Wenzel WW, Jockwer F. Accumulation of heavy metals in plants grown on mineralised soils of the Austrian Alps. Environment Pollution. 1999; 104 (1), pp. 145-155

[76] Tlustoš P, Pavlíková D, Száková J, Fischerová Z, Balík J. Exploitation of fast growing trees in metal remediation. Phytoremediation Rhizoremediation. 2006; pp. 83-102.

[77] Wieshammer G, Unterbrunner R, Baares GT, Zivkovic MF, Puschenreiter M, Wenzel WW. Phytoextraction of $\mathrm{Cd}$ and $\mathrm{Zn}$ from agricultural soils by Salix Ssp. and intercropping of Salix caprea and Arabidopsis halleri. Plant Soil. 2007; 298, 255-264.

[78] Surat H, Aybar M. Ağır metaller ile kirlenmiş alanların onarılmasında kullanılabilecek bitki türleri. Academic Research in Science and Engineering. 2019; Chapter 4.

[79] Smith MM, Nkongolo KK. Physiological and cytological responses of deschampsia cespitosa and populus tremuloides to soil metal contamination. Water Air Soil Pollution. 2015; 226: 125

[80] Wang YD, Greger M. Clonal differences in mercury tolerance, accumulation, and distribution in willow. Journal Environment Quality. 2004; 33, 1779-1785.

[81] Tlustoš P, Pavlíková D, Száková J, Fischerová Z, Balík J. Exploitation of fast growing trees in metal remediation. Phytoremediation Rhizoremediation. 2006; pp. 83-102.

[82] Özer S, Yılmaz H, Kaya Y. Determination of the diversity of grassy and woody plant species in Sarıkamış/Turkey district and evaluation of their usability in planning and design attempts Biological Diversity and Conservation 2009; 2 / 3

[83] Y1lmaz H. ve Yilmaz H. .Karayolu Şevlerinde Doğal Olarak Yetişen Odunsu Bitkilerin Kullanım Alanlarının İrdelenmesi. Erzurum-Uzundere Örneği. Süleyman Demirel Üniversitesi Orman Fakültesi Dergisi. 2009;1: 101-111

[84] Güler N. Çevre Ve Orman Bakanlığı Vize Orman İşletme Müdürlüğü, İğneada ve Çevresi Fauna Revizyonu. K1klareli, Vize.2013.

[85] Tuttu G, Aytaş İ, Dilaver Z. Use Opportunities of Some Natural Herbaceous Plants of Cankiri Province in Landscape Applications International Journal of Scientific and Technological Research www.iiste.org ISSN 2422-8702 (Online), DOI: 10.7176/JSTR/5-3-16 Vol.5, No.3, 2019

[86] Surat H. .Artvin'de doğal olarak yetişen bazı tıbbiaromatik ve ekonomik değere sahip odunsu bitkilerin peyzaj mimarlığında kullanım alanlarının değerlendirilmesi. Uluslararası Sosyal Araştırmalar Dergisi. 2020; Cilt: 13 Sayı: 74 Y11: 2020 \& Volume: 13 Issue: 74

[87] Oldfield EE, Warren RJ, Felson AJ, Bradford MA. Challenges and future directions in urban afforestation. Journal Applied Ecology 2013; 50, 1169-1177.

[88] Merlot S, Garcia de la Torre VS, Hanikenne M. Physiology and molecular biology of trace element hyperaccumulation. Agromining: Farming for Metals. 2018; pp 93-116

[89] Wu D, Yu X, Lai M, Feng J, Dong X, Peng W, Su S, Zhang $X$, Wan L, Jacobs DF, Zeng S. . Diversified effects of co-planting landscape plants on heavy metals pollution remediation in urban soil amended with sewage sludge. Journal of Hazardous Materials. 2021; Volume 403, 5

[90] Wan X, Lei M, Chen T, Yang J. Intercropped Pteris vittata L. and Morus alba L. presents a safe utilization mode for arsenic-contaminated soil. Sci. Total Environ. 2017; 579, 1467-1475.

[91] Zeng P, Guo Z, Xiao X, Peng C, Feng W, Xin L, $\mathrm{Xu} \mathrm{Z}$. Phytoextraction potential of Pteris vittata $\mathrm{L}$. co-planted with woody species for $\mathrm{As}, \mathrm{Cd}, \mathrm{Pb}$ and $\mathrm{Zn}$ in contaminated soil. Sci. Total Environ. 2019; 650, 594-603.

[92] Cid CV, Pignata ML, Rodriguez JH. Effects of cocropping on soybean growth and stress response in lead-polluted soils. Chemosphere. 2020246, 125833. 